This is a post-peer-review, pre-copyedit version of an article published in HorneroMéndez D. (2020) A Routine Method for the Extraction and HPLC-DAD Profiling of Major Plant and Food Carotenoids. In: Rodríguez-Concepción M., Welsch R. (eds) Plant and Food Carotenoids. Methods in Molecular Biology, vol 2083. Humana, New York, NY The final authenticated version is available online at: https://doi.org/10.1007/978-1-4939-9952-1_9

\title{
A Routine Method for the Extraction and HPLC-DAD Profiling of Major Plant and Food Carotenoids
}

Dámaso Hornero-Méndez

\begin{abstract}
Carotenoids are ubiquitously present in Nature, and especially in plants and derived foods. The carotenoid profiling is necessary to understand relevant aspects in relation to their biochemistry and genetics, as well as their important roles on human health and animal ecophysiology. Here we propose a simple methodology for the routine extraction and efficient HPLC separation of the most common plant and food carotenoids from plant and animal origins.
\end{abstract}

\section{Key words}

HPLC UV/Visible DAD Carotenoids Carotenes Xanthophylls

\section{Introduction}

Among natural pigments, carotenoids are those more ubiquitously found in living organisms [1]. Carotenoids are responsible for the yellow, orange, and red colors of most fruits and vegetables, including fruits, flowers, roots, leaves, and seeds; and also of some animal tissues and derived foods (i.e., egg-yolk, skin, etc.) [2]. The most common carotenoids are C40 isoprenoids characterized by a polyene skeleton with a long conjugated double-bond system, which constitutes the chromophore. Longer (C50 bacterial carotenoids) and shorter (for instance apocarotenoids) chain carotenoids are also found. About 750 naturally occurring carotenoids have been isolated and described [1]. Carotenoids can only be synthesized de novo by plants, and some bacteria and fungi. In contrast, animals must necessarily uptake carotenoids from diet since they are unable to synthesize them [3]. Carotenoids play essential roles in the light-harvesting process and the photoprotection mechanisms of plants. Moreover, after ingestion by animals, carotenoids exert a wide range of health-promoting functions and actions such as provitamin A (only some of them), antioxidant, reduction in the risk of developing cardiovascular and other degenerative diseases (such as age-related macular degeneration (AMD) and cataracts), enhancement of the immune response, and cell protection against free radicals $[3,4]$. 
Thus, the qualitative and quantitative analysis of carotenoids is of paramount importance for the investigation of all these associated aspects. Chromatography, and especially HPLC, has always been the choice methodology for attaining this task. In fact, the invention and development of the initial chromatography technique by Mikhail Tswett in the early 1900s was closely linked to the study of chloroplast pigments $[5,6]$. The first HPLC application for the separation of carotenoids was reported by Stewart and Wheaton in 1971 for the investigation of the carotenoid composition of Citrus extracts [7]. Since then, important advances and innovations have been made in the HPLC technique, including the development of new stationary phases well as sensible, selective and robust detectors (mainly DAD and MS detectors), which have been applied to the carotenoid research field [8]. Consequently, a vast diversity of HPLC methods can be found in the carotenoid literature. The protocol here presented has been used routinely in the author's lab during the last 25 years for analysing carotenoids in great variety of plant and food matrices [9]. This method was firstly developed for the separation and quantification of the complex carotenoid profile in red pepper fruits (Capsicum annuum) and derived products such as paprika powder and oleoresin [9]. The HPLC method uses a $\mathrm{C} 18$ reverse-phase and a binary gradient composed by acetone and deionized water, providing a rapid ( $\beta$-carotene elutes at $21 \mathrm{~min}$ ) and very reproducible separation. The optimised conditions have given excellent results when used for the major carotenoid analysis in a wide variety of samples such as green vegetables, apple fruits, potato tubers, cereal grains, dates, strawberry fruits, rose hips, sarsaparilla berries, fungi extracts, and orange juice $[9,10$, $11,12,13,14,15,16,17,18,19,20]$. Additionally, the present HPLC conditions have been applied to the analysis of carotenoids in fungi and bacteria [21, 22], and in animal samples such as plasma, egg-yolk, and skin [23, 24, 25].

\section{Materials}

Reagents should be at least of analytical grade, unless stated otherwise.

\subsection{Sample Pretreatment}

Plant material and food-related samples can be analyzed either in fresh (solid or liquid) or dehydrated state (see Note 1). Solid and semisolid materials, such as fruits and vegetables, should be chopped and mixed with a household blender right before extraction. In the case of harder material (i.e., cereals and other seeds) a lab mill can be used (see Note 2).

1. Household blender.

2. Lab mill.

3. Lyophilizer.

\subsection{Extraction of Carotenoids}

1. Homogenizer (Ultraturrax model T-25 or similar).

2. Solvent for extraction: Acetone containing 0.1\% butylated hydroxytoluene (BHT).

3. Diethyl ether containing 6 ppm BHT (see Note 3). 
4. $\mathrm{NaCl}$ solution $(10 \% \mathrm{w} / \mathrm{v})$.

5. Anhydrous $\mathrm{Na}_{2} \mathrm{SO}_{4}$ solution ( $\left.2 \% \mathrm{w} / \mathrm{v}\right)$.

6. Refrigerated centrifuge with rotor for $50 \mathrm{~mL}$ and $15 \mathrm{~mL}$ tubes.

7. Refrigerated centrifuge with rotor for microcentrifuge tubes $(1.5-2 \mathrm{~mL})$ with a minimum centrifuge force of $12,000 \times \mathrm{g}$.

8. $15 \mathrm{~mL}$ and $50 \mathrm{~mL}$ centrifuge tubes (Falcon type or similar).

9. $1.5 \mathrm{~mL}$ microcentrifuge tubes (Eppendorf type or similar).

10. Separation funnel (1 L).

11. Vortex.

12. Anhydrous $\mathrm{Na}_{2} \mathrm{SO}_{4}$ (solid).

13. Rotary evaporator.

14. Nitrogen (gas).

15. Acetone (HPLC grade).

16. Sonication bath.

17. Sample vials for HPLC (see Note 4).

\subsection{Saponification of Carotenoid Extract}

1. $15 \mathrm{~mL}$ centrifuge tube (Falcon type or similar).

2. Diethyl ether (containing 6 ppm BHT).

3. $\mathrm{KOH}-$ methanol solution $(10 \% \mathrm{w} / \mathrm{v})$.

4. Vortex.

5. $\mathrm{pH}$ test strips.

6. Anhydrous $\mathrm{Na}_{2} \mathrm{SO}_{4}$ (solid).

7. Nitrogen (gas).

8. Acetone (HPLC-grade).

\subsection{High-Performance Liquid Chromatography (HPLC)}

1. HPLC equipment with a diode array detector (see Note 5). In our case the HPLC system consisted of a Waters 2695 Alliance chromatograph fitted with a Waters 2998 photodiode array detector (DAD), and controlled with Empower2 software (Waters Corporation, Milford Massachusetts, USA). 
2. Solvent A: Acetone (HPLC-grade).

3. Solvent B: Deionized water (HPLC-grade deionized ultrapure water produced with a Milli-Q Advantage A10 system, Merck Millipore, Madrid, Spain).

4. HPLC column. A reversed-phase C18 column $(200 \mathrm{~mm} \times 4.6 \mathrm{~mm}$ i.d., $3 \mu \mathrm{m}$, Mediterranea SEA18; Teknokroma, Barcelona, Spain), fitted with a guard column of the same packing material, should be used (see Note 6).

\subsection{Preparation of Calibration Curves}

1. UV/visible (UV/Vis) spectrophotometer. In our case the system consisted of a HewlettPackard UV/Vis diode array spectrophotometer model 8452A.

2. Quartz cuvette $(0.5 \mathrm{~mL})$.

3. $1 \mathrm{~mL}$ volumetric flasks.

4. Carotenoid standards (see Note 7).

5. Solvents (analytical-grade) for individual stock solutions of carotenoids: petroleum ether, ethanol, $n$-hexane.

6. Acetone (HPLC-grade).

\section{Methods}

\subsection{General Precautions}

Carotenoids are labile compounds which are prone to degradation upon exposure to oxygen and light, thus precautions should be taken to minimize the adverse effects of these factors. It is highly recommended that all operations should be carried out under dimmed light to prevent isomerization and photodegradation of carotenoids. Follow "Good Laboratory Practice" procedures so that all operations involving the manipulation of solvents are performed in a fume hood.

\subsection{Extraction of Carotenoids (Standard Procedure)}

1. Sample size. One to three grams taken from a homogeneous and representative sample is generally sufficient to provide accurate and reproducible data (see Note 8). In the case of dehydrated samples the sample size can be scaled down by a factor of 5-10 (see Note 9).

2. Place sample in a $50 \mathrm{~mL}$ centrifuge tube (Falcon tube or similar) and extract it with $20 \mathrm{~mL}$ of acetone (containing $0.1 \%$ BHT) by using a homogenizer during $1 \mathrm{~min}$ (see Note 10). If an internal standard (IS) is used, this should be added at this step (the IS amount should be adjusted to the expected average carotenoid content) (see Note 11). 
3. Separate extract from sample debris by centrifugation at $4500 \times \mathrm{g}$ at $4{ }^{\circ} \mathrm{C}$ during $5 \mathrm{~min}$.

4. Repeat the extraction procedure 3-4 times until complete extraction of color (see Note 12).

5. Collect and pool extracts into a separation funnel ( $1 \mathrm{~L}$ volume).

6. Add $50 \mathrm{~mL}$ of diethyl ether (containing $6 \mathrm{ppm} \mathrm{BHT)} \mathrm{and} 100 \mathrm{~mL}$ of $\mathrm{NaCl}$ solution ( $10 \% \mathrm{w} / \mathrm{v}$ ), and shake vigorously during $1 \mathrm{~min}$ to facilitate carotenoid transfer to ether phase. Allow to stand for the separation of two phases, and discard the aqueous phase (lower phase).

7. The upper phase, containing the carotenoid pigments is washed three additional times with $10 \% \mathrm{NaCl}$ and finally with $2 \%(\mathrm{w} / \mathrm{v}) \mathrm{Na}_{2} \mathrm{SO}_{4}$ solution for removing the water contained in the organic fraction (see Note 13). Aqueous phases are discarded after each washing.

8. Filter the extract through an anhydrous $\mathrm{Na}_{2} \mathrm{SO}_{4}$ bed into a round-bottom flask. Wash the filtering material with additional diethyl ether until no color is observed.

9. Evaporate the extract to dryness under vacuum in a rotary evaporator at temperature not higher than $30^{\circ} \mathrm{C}$ (see Note 14 ).

10. The dry extract is dissolved in $3-5 \mathrm{~mL}$ of acetone (see Note 15$)$ and an aliquot $(0.5 \mathrm{~mL})$ is stored at $-30^{\circ} \mathrm{C}$ until HPLC analysis (see Note 16 ).

11. Extraction should be performed in at least triplicate $(n=3)$.

\subsection{Extraction of Carotenoids (Microscale Procedure)}

1. Sample size. Use $0.2-0.5 \mathrm{~g}$ depending on the sample nature (see Note 17).

2. Place sample in a $15 \mathrm{~mL}$ centrifuge tube (Falcon tube or similar) and extract carotenoids with $3 \mathrm{~mL}$ of acetone (containing 0.1\% BHT) by using a homogenizer during $1 \mathrm{~min}$ (see Notes 9 and 10). Add IS in this step (if used).

3. Separate extract by centrifugation at $4500 \times \mathrm{g}$ at $4{ }^{\circ} \mathrm{C}$ during $5 \mathrm{~min}$.

4. Repeat the extraction procedure 3-4 times until complete extraction of color.

5. Collect and pool extracts into a clean tube.

6. Reduce solvent volume down to $2-3 \mathrm{~mL}$ under a gentle nitrogen stream (see Note 18).

7. Add $3 \mathrm{~mL}$ of diethyl ether and $4 \mathrm{~mL}$ of $\mathrm{NaCl}$ solution $(10 \% \mathrm{w} / \mathrm{v})$, and shake vigorously during $30 \mathrm{~s}$ to facilitate carotenoid transfer to the ether phase.

8. Separate phases by centrifugation at $4500 \times \mathrm{g}$ at $4{ }^{\circ} \mathrm{C}$ during $5 \mathrm{~min}$.

9. Transfer the upper phase (diethyl ether phase), with a glass Pasteur pipette, into a clean tube, and repeat (2-3 times) the extraction of the aqueous phase with $2 \mathrm{~mL}$ of diethyl ether. Discard the lower phase (aqueous phase).

10. Collect the ether phases and evaporate to dryness under vacuum in a rotary evaporator at temperature not higher than $30^{\circ} \mathrm{C}$. Alternatively, solvent can be evaporated under N2 stream. 
11. Dissolve the dry extract in $0.5-1.0 \mathrm{~mL}$ of acetone (see Note 15 ) and stored at $-30^{\circ} \mathrm{C}$ until HPLC analysis.

12. Extraction should be performed in at least triplicate.

\subsection{Saponification}

If saponification is required for the hydrolysis of lipids and carotenoid esters, the following micro-scale procedure can be used.

1. $1 \mathrm{~mL}$ of the pigment extract obtained in Subheading 3.2 (step 10) is placed in a $15 \mathrm{~mL}$ centrifuge tube (Falcon type or similar) and dried under a nitrogen stream (see Note 19).

2. Add $2 \mathrm{~mL}$ of diethyl ether and $1 \mathrm{~mL}$ of $10 \%(\mathrm{w} / \mathrm{v}) \mathrm{KOH}-$ methanol.

3. Shake the mixture in a vortex for $30 \mathrm{~s}$ and left to react for $20 \mathrm{~min}$ at room temperature under nitrogen atmosphere and with periodic shaking (see Note 20).

4. Add $8 \mathrm{~mL}$ of distilled water for washing, and separate phases by centrifugation (at $4500 \times \mathrm{g}$ at $4{ }^{\circ} \mathrm{C}$ during $5 \mathrm{~min}$ ).

5. Discard the lower aqueous phase and repeat the washing operation (see Note 13) until the $\mathrm{pH}$ of the aqueous phase is neutral (use $\mathrm{pH}$ test strips).

6. Discard the lower phase (last washing).

7. Filter the ether phase through an anhydrous $\mathrm{Na}_{2} \mathrm{SO}_{4}$, and rinse the filtering material with more diethyl ether. Collect the filtrate in a clean test tube.

8. Evaporate the ether to dryness under a nitrogen stream.

9. Dissolve the extract in $1 \mathrm{~mL}$ of acetone and store at $-30^{\circ} \mathrm{C}$ until subsequent chromatographic analysis.

\subsection{High Performance Liquid Chromatography (HPLC)}

1. Equilibrate the HPLC equipment to the initial solvent conditions ( $75 \%$ solvent $A$ and $25 \%$ solvent $\mathrm{B}$ ) and $25^{\circ} \mathrm{C}$ for column temperature.

2. Set flow rate at $1 \mathrm{~mL} / \mathrm{min}$.

3. Prior to injection, samples are centrifuged at $>13,000 \times \mathrm{g}$ for $5 \mathrm{~min}$ at $4{ }^{\circ} \mathrm{C}$ for particle removal (see Notes 21 and 22).

4. Inject $10 \mu \mathrm{L}$ of sample into the HPLC system (see Notes 23 and 24). 
5. Run the binary-gradient elution profile: Initial conditions (75\% A; $25 \% \mathrm{~B})$ increases linearly to $95 \% \mathrm{~A}$ in $10 \mathrm{~min}$, then hold $95 \% \mathrm{~A}$ for $7 \mathrm{~min}$ and raises to $100 \% \mathrm{~A}$ in $3 \mathrm{~min}$, and is maintained constant $(100 \% \mathrm{~A})$ for $3 \mathrm{~min}$ (see Note 25$)$. Initial conditions are restored in $5 \mathrm{~min}$.

6. Detection is performed at $450 \mathrm{~nm}$, and the online spectra are acquired in the $330-700 \mathrm{~nm}$ wavelength range with a resolution of $1.2 \mathrm{~nm}$.

7. Integrate chromatogram at $450 \mathrm{~nm}$ (see Note 26), and record peak areas for quantification according to calibration curves prepared with pure carotenoid standards (see Subheading 3.5). As examples, Figs. 1-5 show the HPLC chromatograms and the online UV/Vis spectra obtained for carotenoid extracts prepared from spinach leaves, tomato fruits, red pepper fruits, sarsaparilla berries and egg-yolk, respectively.

8. Calculate concentration from calibration curves (see Note 27) and give quantitative result in adequate units (i.e., $\mu \mathrm{g} / \mathrm{g}, \mathrm{mg} / \mathrm{kg}, \mathrm{mg} / 100 \mathrm{~g}, \mathrm{mg} / \mathrm{L}$, in either fresh or dry weight basis).

\subsection{Preparation of Calibration Curves}

1. Prepare a stock solution for each carotenoid standard by dissolving a small amount (300$500 \mu \mathrm{g}$ ) in $5 \mathrm{~mL}$ of acetone or petroleum ether for xanthophylls or carotenes, respectively.

2. Use UV/Vis spectrophotometry for measuring the concentration of the stock solutions by using Beer-Lambert law and the specific absorption coefficient $\left(A_{1 \mathrm{~cm}}^{1 \%}\right)$ for each carotenoid in a particular solvent at a characteristic wavelength $(\lambda(\mathrm{nm}))$. An appropriate dilution of the stock solution with the selected solvent is needed. Table 1 presents a list of common carotenoids including specific absorption coefficients, wavelength for measurement and solvent. Check the literature for a more detailed list $[1,26,27]$.

3. Calculate the concentration $(\mu \mathrm{g} / \mathrm{mL})$ of the stock solution from the following expression

$$
C=\frac{A \times D F \times 10^{4}}{A_{1 \mathrm{~cm}}^{1 \%}}
$$

where $C$ is the concentration $(\mu \mathrm{g} / \mathrm{mL}), A$ is the absorbance at the selected $\lambda(\mathrm{nm}), A_{1 \mathrm{~cm}}^{1 \%}$ is the specific absorption coefficient, and DF is the dilution factor.

4. For each carotenoid prepare a set of eight working solutions in the concentration range $0.05-40 \mu \mathrm{g} / \mathrm{mL}$ by diluting appropriated volumes of the stock solution with acetone.

5. Centrifuge an aliquot of each working solution at $>13,000 \times \mathrm{g}$ for 5 min at $4{ }^{\circ} \mathrm{C}$.

6. Inject $10 \mu \mathrm{L}$ of each working solution into the HPLC system. Do this by triplicate.

7. Integrate chromatograms at $450 \mathrm{~nm}$ (or other selected wavelength for particular carotenoids) and annotate peak areas. 
8. Plot peak area versus concentration $(\mu \mathrm{g} / \mathrm{mL})$ to calculate the calibration curve expression by the "linear least-squares" method (see Note 27). Calibration curve is given as follows:

$$
\text { Peak area }=\text { Response factor } \times C(\mu \mathrm{g} / \mathrm{mL})+\text { Intercept }
$$

\section{Notes}

1. Lyophilization, also known freeze-drying, is the preferred method for dehydrating or drying biological materials as it preserves intact most of chemical constituents.

2. Avoid the increase of temperature by using short milling times.

3. Commercial diethyl ether is usually supplied with added butylated hydroxytoluene (BHT), an antioxidant which reduces the formation of peroxides.

4. If possible, amber glass vials should be used in order to prevent the photodegradation of pigments.

5. As minimum requirements, the HPLC equipment should deliver binary solvent gradients, control constant column temperature and should have an UV/Vis spectrophotometric detector (if possible a diode array detector (DAD)).

6. Similar reversed-phase $\mathrm{C} 18$ columns from other suppliers can be used, however selectivity may change in some cases and elution order can be affected. For example, in our column zeaxanthin elutes earlier than lutein, but in most C18 columns zeaxanthin elutes right after lutein. Therefore, elution order should be checked during method implementation by using either carotenoid standards or natural extracts with well-known carotenoid profile.

7. Traditionally, few carotenoids have been commercially available in pure form. Consequently, authentic reference carotenoid compounds have been isolated from natural sources with wellknown carotenoid profile and where the aimed compound, if possible, is a major one. A combination of solvent partition and chromatographic techniques (TLC, open column chromatography, analytical and semipreparative HPLC, etc.) are used for this purpose. Guidance for the selection of appropriate natural sources, and recommendations for analytical procedures for isolation, purification and identification are found in the literature $[8,9,27,28$, $29,30,31]$. In the last decade, reliable commercial suppliers have become available (e.g., CaroteNature $\mathrm{GmbH}$, Extrasynthese SAS, and Sigma-Aldrich). Highly experienced carotenoid labs still prefer to isolate their own carotenoid standards since in most cases the purity is higher than the commercial ones.

8. Follow adequate sampling procedures for guaranty representativeness as well as to minimize errors during quantification. For carotenoids this has been recently reviewed by Rodríguez-Amaya [30].

9. In order to improve the extraction of carotenoids, dehydrated and lyophilized samples should be reconstituted with water up to the level present in the raw material. As a general rule five parts of water are added for one part of dry sample. 
10. Select a homogenization speed so that the formation of foam is minimized and consequently reduce the degradation pigments by decreasing contact with air.

11. $\beta$-Apo-8'-carotenal is the most common carotenoid used as IS. The carotenoid used as IS needs to conform to some important requirements, the first one being its absence in the sample to be studied. The full of requirements for carotenoid IS, as well as guidance in their use can be found in Khachik [8].

12. The dispersing tool used for homogenization is cleaned during every successive extraction.

13. The organic phase frequently reduces its volume due to the high volatility of diethyl ether. If this happens the original diethyl ether volume should be approximately restored with more solvent before proceeding to next step.

14. If some water residues are still present after solvent evaporation, add a few milliliters (3-5 $\mathrm{mL}$ ) of absolute ethanol and evaporate again in the rotary evaporator. The addition of ethanol will facilitate the evaporation of water by forming an azeotrope.

15. Introduce the sample into a sonication bath during $10 \mathrm{~s}$ for ensuring solubilization of carotenoids.

16. If carotenoids are not analyzed immediately after the extraction, samples should be stored at $-30^{\circ} \mathrm{C}$ (or lower) until chromatographic analysis (HPLC) in order to prevent degradation of carotenoids. If possible, the air from the sample vial should be displaced with a stream of $\mathrm{N}_{2}$

17. A preliminary test sample should be analyzed for an adequate selection of sample size.

18. A heating thermo-block for tubes at temperature $<30^{\circ} \mathrm{C}$ can be used to speed up the process.

19. In the case of the extract prepared by the "Microscale procedure" (Subheading 3.4), the entire extract can be submitted to saponification.

20. A single phase should be obtained. In the event that two phases are separated, add a few drops of methanol until a single phase is formed, and mix thoroughly.

21. Alternatively, samples can be filtered through $0.45 \mu \mathrm{m}$ nylon filters. However, this practice is not recommended when using volatile solvents as evaporation during extract manipulation will cause overestimation of carotenoid content due to sample concentration.

22. Samples which have been kept at low temperature in the freezer should be left at room temperature for 5-10 min to ensure solubilization of pigments. For the same reason these samples cannot be centrifuged right out of the freezer.

23. If available, the injection should be achieved with an automatic injector for better reproducibility and automatization. In addition the sample compartment of the automatic injector should be fitted with a cooling system for sample vials in order to prevent thermodegradation as well as sample concentration due to solvent evaporation. The recommended temperature range is $10-15^{\circ} \mathrm{C}$. Lower temperature should not be used as carotenoid can precipitate in the vial thus leading to errors in the quantification. 
24. Avoid using injection volumes higher than $20 \mu \mathrm{L}$ for preventing peak distortion during chromatography.

25. If xanthophyll esters are present in the sample and saponification has not been performed then the last step of the gradient elution at $100 \%$ A should be increased to $10 \mathrm{~min}$ to allow separation and detection of the very nonpolar diesters.

26. In general, $450 \mathrm{~nm}$ is a detection wavelength that can be used for most carotenoids. However, for some particular carotenoids the detection wavelength needs to be adequate to their chromophore properties. For instance, this is the case of phytoene and phytofluene with absorption maxima at 286 and $348 \mathrm{~nm}$, respectively.

27. Calibration curves can be used for the estimation of other carotenoids such as the case of cis isomers (or Z- isomers), which are usually quantified using the calibration curve of the trans (or all-E isomers) counterpart.

\section{Acknowledgments}

The author thanks to the Spanish Government (projects AGL2017-85368P and CaRed Network BIO2015-71703-REDT and BIO2017-90877-REDT) for financial support. 


\section{References}

1. Britton G, Liaaen-Jensen S, Pfander H (2008) Carotenoids handbook. Birkhäuser Verlag, Basel

2. Britton G, Hornero-Méndez D (1997) Carotenoids and colour in fruit and vegetables. In: Tomás-Barberán FA, Robins RJ (eds) Phytochemistry of fruit and vegetables. Clarendon Press, Oxford, pp 11-27

3. Rodriguez-Concepcion M, Avalos J, Bonet ML, Boronat A, Gomez-Gomez L, Hornero-Mendez D, Limon MC, Meléndez-Martínez AJ, Olmedilla-Alonso B, Palou A, Ribot J, Rodrigo MJ, Zacarias L, Zhu C (2018) A global perspective on carotenoids: metabolism, biotechnology, and benefits for nutrition and health. Prog Lipid Res 70:62-93.

https://doi.org/10.1016/j.plipres.2018.04.004

4. Britton G, Liaaen-Jensen S, Pfander H (2009) Carotenoids, Nutrition and health, vol 5. Birkhäuser Verlag, Basel, Switzerland

5. Ettre LS, Sakodynskii KI (1993) M. S. Tswett and the discovery of chromatography I: early work (1899-1903). Chromatographia 35(3):223-231. https://doi.org/10.1007/BF02269707

6. Ettre LS, Sakodynskii KI (1993) M. S. Tswett and the discovery of chromatography II: completion of the development of chromatography (1903-1910). Chromatographia 35(5):329338. https://doi.org/10.1007/BF02277520

7. Stewart I, Wheaton TA (1971) Continuous flow separation of carotenoids by liquid chromatography. J Chromatogr 55:325-336

8. Khachik F (2009) Analysis of carotenoids in nutritional studies. In: Britton G, Liaaen-Jensen S, Pfander H (eds) Carotenoids, vol 5: Nutrition and health, vol 5. Birkhäuser Verlag, Basel, Switzerland, pp 7-44

9. Mínguez-Mosquera MI, Hornero-Méndez D (1993) Separation and quantification of the carotenoid pigments in red peppers (Capsicun annuum L.), paprika and oleoresin by reversedphase HPLC. J Agric Food Chem 41:1616-1620

10. Atienza SG, Ballesteros J, Martin A, Hornero-Méndez D (2007) Genetic variability of carotenoid concentration and degree of esterification among tritordeum (xTritordeum Ascherson et Graebner) and durum wheat accessions. J Agric Food Chem 55(10):4244-4251. https://doi.org/10.1021/jf070342p

11. Delgado-Pelayo R, Gallardo-Guerrero L, Hornero-Méndez D (2014) Chlorophyll and carotenoid pigments in the peel and flesh of commercial apple fruit varieties. Food Res Int 65:272-281. https://doi.org/10.1016/j.foodres.2014.03.025

12. Delgado-Pelayo R, Gallardo-Guerrero L, Hornero-Méndez D (2016) Carotenoid composition of strawberry tree (Arbutus unedo L.) fruits. Food Chem 199:165-175.

https://doi.org/10.1016/j.foodchem.2015.11.135 
13. Delgado-Pelayo R, Hornero-Méndez D (2012) Identification and quantitative analysis of carotenoids and their esters from sarsaparilla (Smilax aspera L.) berries. J Agric Food Chem 60(33):8225-8232. https://doi.org/10.1021/jf302719g

14. Fernandez-Orozco R, Gallardo-Guerrero L, Hornero-Méndez D (2013) Carotenoid profiling in tubers of different potato (Solanum sp) cultivars: accumulation of carotenoids mediated by xanthophyll esterification. Food Chem 141(3):2864-2872.

https://doi.org/10.1016/j.foodchem.2013.05.016

15. Hornero-Méndez D, Mínguez-Mosquera MI (2000) Xanthophyll esterification accompanying carotenoid overaccumulation in chromoplast of Capsicum annuum ripening fruits is a constitutive process and useful for ripeness index. J Agric Food Chem 48(5):16171622. https://doi.org/10.1021/jf9912046

16. Hornero-Méndez D, Mínguez-Mosquera MI (2000) Carotenoid pigments in rosa mosqueta hips, an alternative carotenoid source for foods. J Agric Food Chem 48(3):825-828. https://doi.org/10.1021/jf991136n

17. Mellado-Ortega E, Hornero-Méndez D (2015) Carotenoid profiling of Hordeum chilense grains: the parental proof for the origin of the high carotenoid content and esterification pattern of tritordeum. J Cereal Sci 62:15-21. https://doi.org/10.1016/j.jcs.2014.12.005

18. Mellado-Ortega E, Hornero-Méndez D (2012) Isolation and identification of lutein esters, including their regioisomers, in tritordeum (xTritordeum Ascherson et Graebner) grains: evidence for a preferential xanthophyll acyltransferase activity. Food Chem 135(3):1344-1352. https://doi.org/10.1016/j.foodchem.2012.05.046

19. Mattera MG, Hornero-Méndez D, Atienza SG (2017) Lutein ester profile in wheat and tritordeum can be modulated by temperature: evidences for regioselectivity and fatty acid preferential of enzymes encoded by genes on chromosomes 7D and 7H(ch). Food Chem 219:199-206. https://doi.org/10.1016/j.foodchem.2016.09.133

20. Boudries H, Kefalas P, Hornero-Méndez D (2007) Carotenoid composition of Algerian date varieties (Phoenix dactylifera) at different edible maturation stages. Food Chem 101(4):13721377. https://doi.org/10.1016/j.foodchem.2006.03.043

21. Avalos J, Pardo-Medina J, Parra-Rivero O, Ruger-Herreros M, Rodriguez-Ortiz R, HorneroMendez D, Limon MC (2017) Carotenoid biosynthesis in fusarium. J Fungi (Basel) 3(3):39. https://doi.org/10.3390/jof3030039

22. Garrido-Fernandez J, Maldonado-Barragan A, Caballero-Guerrero B, Hornero-Mendez D, Ruiz-Barba JL (2010) Carotenoid production in lactobacillus plantarum. Int J Food Microbiol 140(1):34-39. https://doi.org/10.1016/j.ijfoodmicro.2010.02.015

23. Hornero-Mendez D, Cerrillo I, Ortega A, Rodriguez-Grinolo MR, Escudero-Lopez B, Martin F, Fernandez-Pachon MS (2018) Beta-Cryptoxanthin is more bioavailable in humans from fermented orange juice than from orange juice. Food Chem 262:215-220. https://doi.org/10.1016/j.foodchem.2018.04.083 
24. Negro JJ, Grande JM, Tella JL, Garrido J, Hornero D, Donázar JA, Sanchez-Zapata JA, Benítez JR, Barcell M (2002) An unusual source of essential carotenoids. Nature 416:807.

https://doi.org/10.1038/416807a

25. Blanco G, Hornero-Mendez D, Lambertucci SA, Bautista LM, Wiemeyer G, Sanchez-Zapata JA, Garrido-Fernandez J, Hiraldo F, Donazar JA (2013) Need and seek for dietary micronutrients: endogenous regulation, external signalling and food sources of carotenoids in new world vultures. PLoS One 8(6):e65562. https://doi.org/10.1371/journal.pone.0065562

26. Britton G (1995) UV/visible spectroscopy. In: Britton G, Liaaen-Jensen S, Pfander H (eds) Carotenoids, Spectroscopy, vol 1B. Birkhäuser Verlag, Basel, Switzerland, pp 13-62

27. Mínguez-Mosquera MI, Hornero-Méndez D, Pérez-Gálvez A (2002) Carotenoids and provitamin a in functional foods. In: Hurst WJ (ed) Methods of analysis for functional foods and nutraceuticals. CRC Press, Boca Raton, pp 101-157

28. Kimura M, Rodriguez-Amaya DB (2002) A scheme for obtaining standards and HPLC quantification of leafy vegetable carotenoids. Food Chem 78(3):389-398. https://doi.org/10.1016/S0308-8146(02)00203-0

29. Britton G, Young AJ (1993) Methods for the isolation and analysis of carotenoids. In: Young A, Britton G (eds) Carotenoids in photosynthesis. Chapman \& Hall, London, pp 409-457

30. Rodriguez-Amaya DB (2016) Qualitative and quantitative analyses. In: Rodriguez-Amaya DB (ed) Food carotenoids: chemistry, biology, and technology. John Wiley \& Sons, Ltd., London, pp 47-81

31. Schiedt K, Liaaen-Jensen S (1995) Isolation and analysis. In: Britton G, Liaaen-Jensen S, Pfander H (eds) Carotenoids, Isolation and analysis, vol 1A. Birkhäuser Verlag, Basel, Switzerland, pp 81-108 
Table 1. Specific absorption coefficients $\left(A_{1 \mathrm{~cm}}^{1 \%}\right)$ used for quantitative spectrophotometric determination of carotenoids

\begin{tabular}{lccl} 
Carotenoid & \multicolumn{3}{c}{$\lambda(\mathbf{n m})$ for } \\
Antheraxanthin & 2350 & 446 & Ethanol \\
Canthaxanthin & 2200 & 466 & Light petroleum \\
Capsanthin & 2072 & 483 & Benzene \\
Capsorubin & 2200 & 489 & Benzene \\
$\alpha$-Carotene & 2800 & 444 & Light petroleum \\
$\beta$-Carotene & 2592 & 449 & Light petroleum \\
$\beta$-Cryptoxanthin & 2386 & 449 & Light petroleum \\
Lutein & 2550 & 445 & Ethanol \\
Lycopene & 3450 & 470 & Light petroleum \\
Neoxanthin & 2243 & 439 & Ethanol \\
Phytoene & 1250 & 286 & Light petroleum \\
Phytofluene & 1350 & 348 & Light petroleum \\
Violaxanthin & 2250 & 440 & Ethanol \\
Zeaxanthin & 2348 & 449 & Light petroleum \\
\hline
\end{tabular}



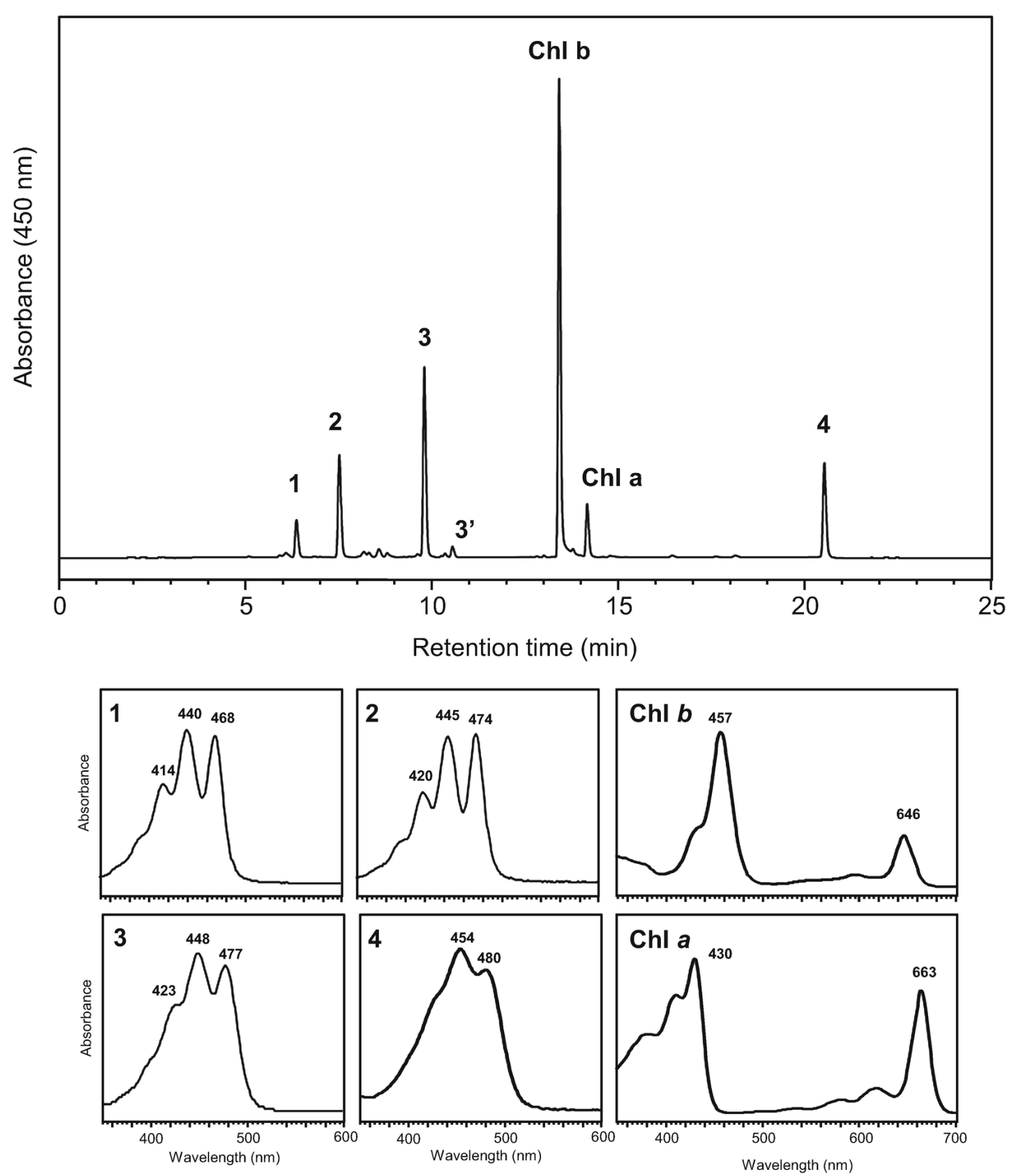

Figure 1.- Chromatogram of the HPLC separation and UV/Vis spectra of the major carotenoids present in an extract obtained from fresh spinach (Spinacia oleracea L.) leaves. Detection wavelength at $450 \mathrm{~nm}$. Peak identities: 1, (9'Z)neoxanthin; 2 , violaxanthin; 3 , lutein; $5, \beta$-carotene. Chlorophyll a (Chl a) and chlorophyll b (Chl b) are also present in the chromatogram 

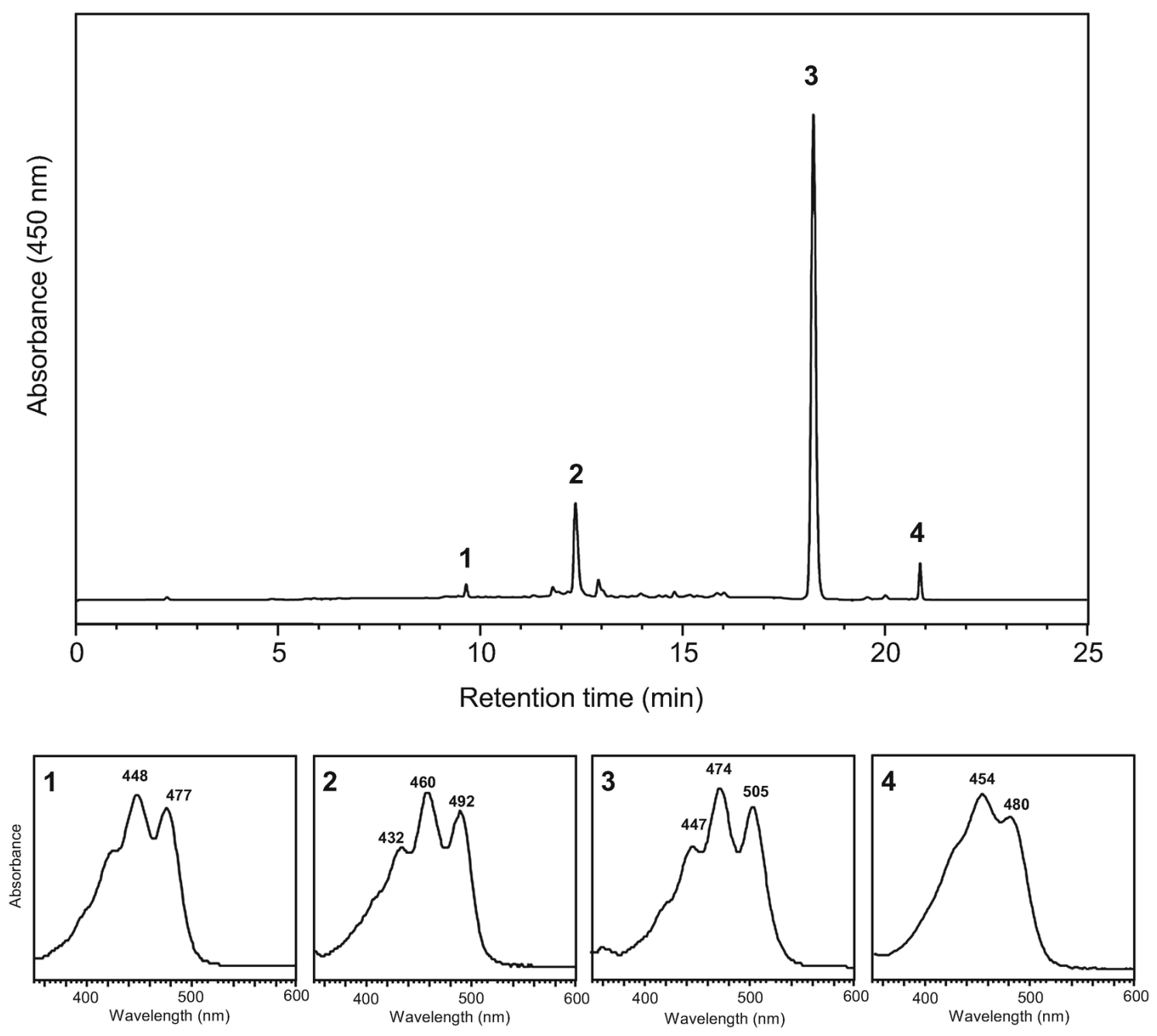

Figure 2.- Chromatogram of the HPLC separation and UV/Vis spectra of the major carotenoids present in an extract obtained from tomato (Solanum lycopersicum L.) fruits. Detection wavelength at $450 \mathrm{~nm}$. Peak identities: 1, lutein; 2 , lycophyll (dihydroxy-lycopene); 3, lycopene; 4, $\beta$-carotene 

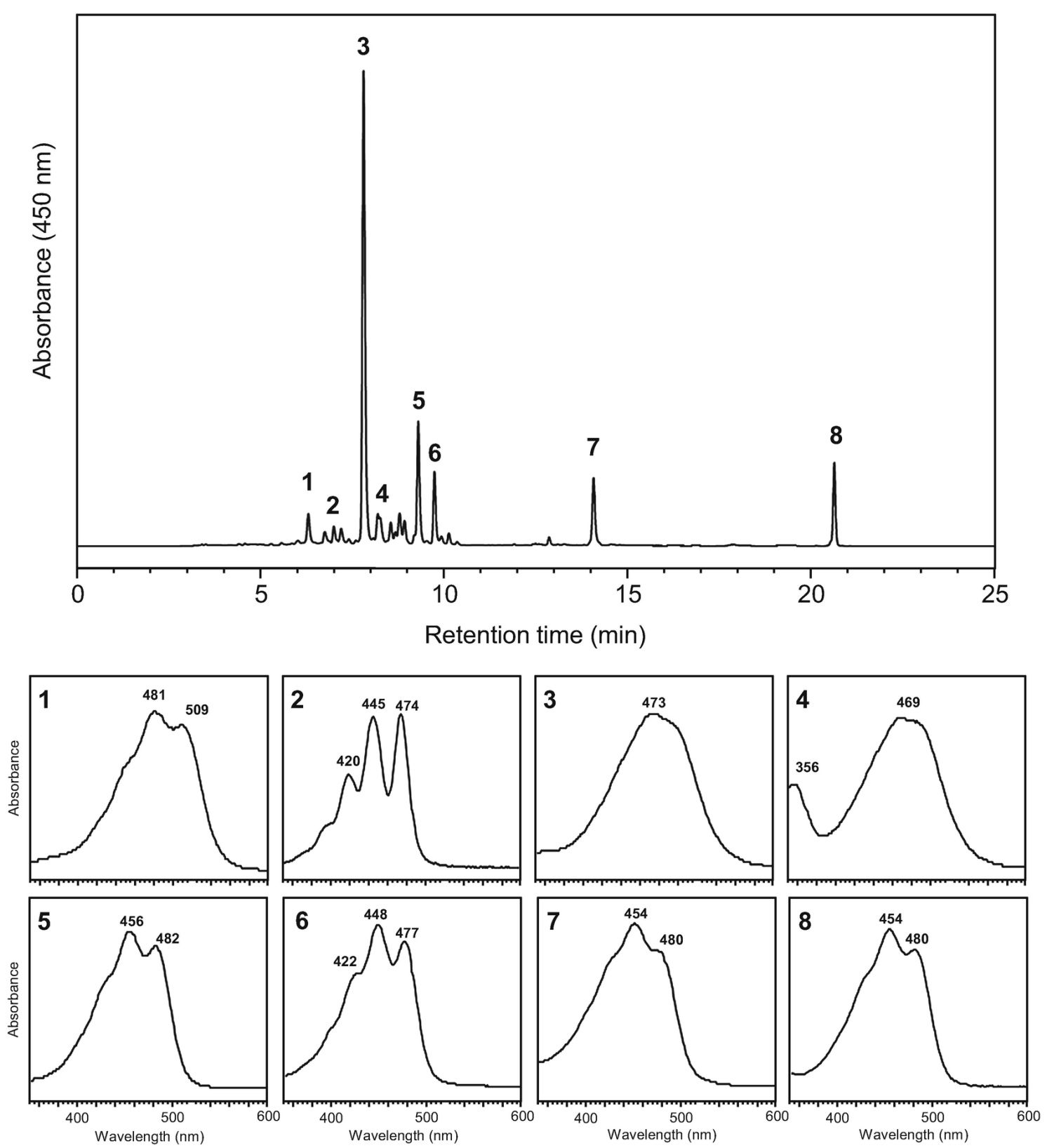

Figure 3.- Chromatogram of the HPLC separation and UV/Vis spectra of the major carotenoids present in an extract (saponified) obtained from red pepper (Capsicum annuum L.) fruits. Detection wavelength at $450 \mathrm{~nm}$. Peak identities: 1, capsorubin; 2 , violaxanthin; 3 , capsanthin; 4 , cis-capsanthin; 5 , zeaxanthin; 6 , cucurbitaxanthin $A ; 7, \beta$-cryptoxanthin; 8 , $\beta$-carotene 

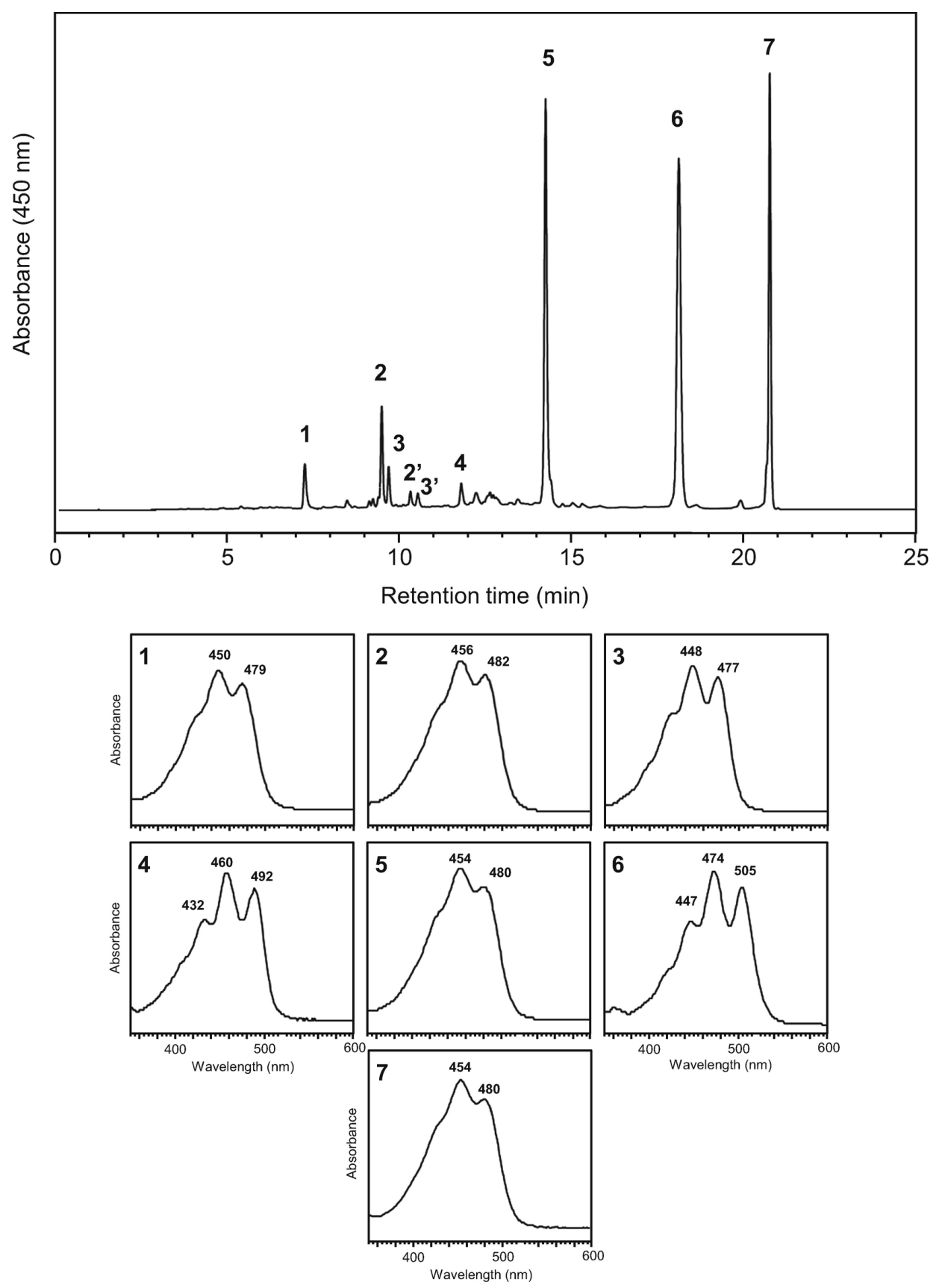

Figure 4.- Chromatogram of the HPLC separation and UV/Vis spectra of the major carotenoids present in an extract (saponified) obtained from sarsaparilla berries (Smilax aspera L.). Detection wavelength at $450 \mathrm{~nm}$. Peak identities: 1 , antheraxanthin; 2, zeaxanthin; 2', cis-zeaxanthin; 3, lutein; 3', cis-lutein; 4, lycophyll; 5, $\beta$-cryptoxanthin; 6, lycopene; 7 , $\beta$-carotene 

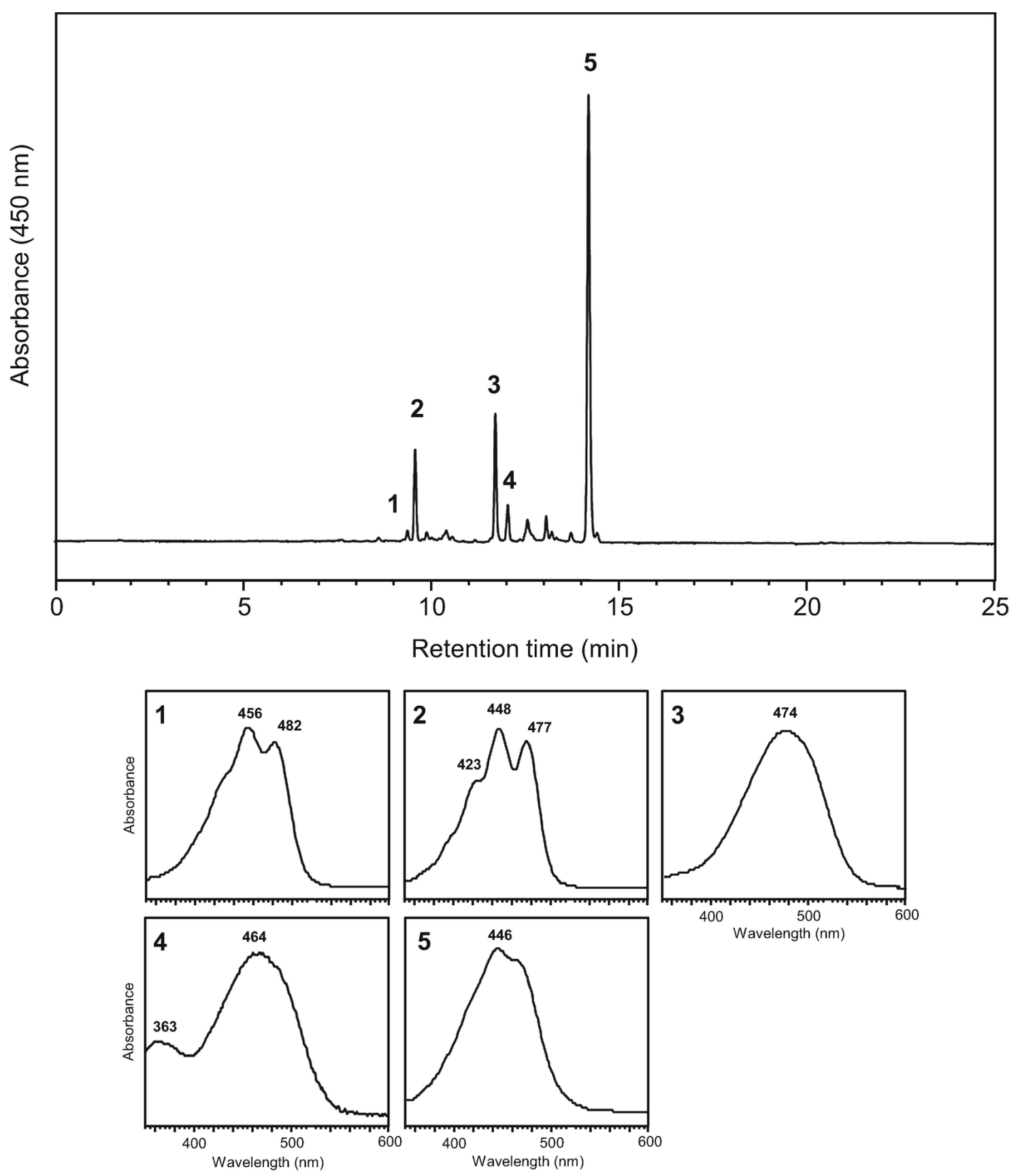

Wavelength $(\mathrm{nm})$

Figure 5.- Chromatogram of the HPLC separation and UV/Vis spectra of the major carotenoids present in an extract obtained from egg-yolks from farmed hens. Detection wavelength at $450 \mathrm{~nm}$. Peak identities: 1, zeaxanthin; 2, lutein; 3, canthaxanthin; 4, cis-canthaxanthin; $5, \beta$-apo-8'-carotenoic acid ethyl ester 